\title{
Spot weld bonding - process behavior of three-sheet steel stack-ups and analysis strategies with online measuring methods
}

\author{
Sascha Brechelt ${ }^{1, *}$, Philipp Neef $^{1}$, Henning Wiche ${ }^{1}$, and Volker Wesling ${ }^{1,2}$ \\ ${ }^{1}$ Clausthal University of Technology, Clausthal Centre of Material Technology, Leibnizstraße 9, 38678 Clausthal-Zellerfeld, \\ Germany \\ ${ }^{2}$ Clausthal University of Technology, Institute of Welding and Machining, Agricolastraße 2, 38678 Clausthal-Zellerfeld, \\ Germany
}

Received: 5 December 2019 / Accepted: 14 December 2019

\begin{abstract}
Due to the increased demands for reducing $\mathrm{CO}_{2}$ emissions, improving fuel efficiency of modern vehicles has been continuously monitored. The body of a typical compact car design has a weight share of approx. $40 \%$. In addition to increasing torsional stiffness and crash safety of the body, the aim is also to reduce the overall weight at the same time. In order to achieve these individual requirements, the use of three-sheet steel stack-ups with adhesive applications for car body construction is one of the current strategies used in automobile manufacturing. Adhesive applications lead to a change in process behavior of resistance spot welding. The effective weldability lobe is reduced and an adjusted preheat current is necessary to reconstitute the weldability of a component. Depending on squeeze time and electrode force the adhesive will be displaced. For an asymmetric sheet stack-up, the electrical resistance for every faying surface is highly differentiated. During welding, a specific characteristic of the electrical resistance is created for each individual material combination. These characteristics can be analyzed by using an online measurement device. In this manuscript, different sheet stack-ups are examined with regard to their weldability lobes and their process behavior. The individual threesheet steel stack-ups used are made of low carbon steel (DX51), HSLA-steel (HX340) and UHS-steel (22MnB5). The corresponding characteristics of electrical resistance will be recorded by using an online measurement device. In addition, the process of adhesive displacement during the squeeze time and the initial welding current are discussed on the basis of the electrical energy generated in the component to be welded. The obtained results contribute to a direct verification of the welding process and an automatic detection of possible imperfect welds.
\end{abstract}

Keywords: Spot weld bonding / resistance spot welding / process monitoring / laser vibrometry

\section{Introduction}

Spot weld bonding is an established technique for the production of car bodies with a focus on a high degree of lightweight construction. Due to increasing demands of weight reduction, torsional stiffness and crash safety, three-sheet steel stack-ups for car body construction are required. Resistance spot welding is made more difficult by the use of highly heterogeneous sheet stack-ups. These stack-ups are made of different materials with disparate surface coatings and a high sheet thickness ratio, as shown in Figure 1. A sufficient joint quality is possible with a maximum sheet thickness ratio of 1:3. However, it should be noted that more complex components (sheet thickness ratio, different materials, and disparate surface conditions) react more sensitively to changing parameters [1-3].

\footnotetext{
* e-mail: sascha.brechelt@tu-clausthal.de
}

The requirements for a weld nugget, produced by resistance spot welding, are specified in [4-6]. An asymmetric three-sheet stack-up made of two thick sheets and a thin outer sheet is shown in Figure 1. During the welding process, the weld nugget in formed in the faying surface II due to the highest electrical resistance and the lowest heat dissipation. Afterwards, the weld nugget expands over the entire cross section. High heat dissipation occurs in the area of the faying surface (I) due to the thin outer sheet metal. Therefore, the expansion of the weld nugget is reduced and achieving a sufficient nugget diameter $d_{\min }$ is made more difficult. Spot weld bonding of asymmetric sheet stack-ups leads to decreasing welding current ranges. The reasons for this are the increased contact resistances at the individual faying surfaces and the behavior of the adhesive displacement. The use of multiple impulses welding can significantly improve the weldability of an adhesive bonded component $[1,7,8]$. 
The process monitoring of resistance spot welding is possible by different examination methods. The online measurement of electrical voltage and current provides information about the course of the electrical resistance and the distribution of electrical energy in a component [7-9]. A time-discrete detection of the electrode widening during welding allows the detection of process irregularities [10]. Using a laser vibrometer $[11,12]$ were able to investigate the electrode movement in different spatial axes.

\section{Test facility}

The experiments are based on a resistance spot welding system with medium frequency inverter. Electrode caps made of the material $\mathrm{CuCr} 1 \mathrm{Zr}$ and the tip size ISO 5821 F1-16-20-40-6 are used (Fig. 2).

During welding, the absolute electrical current and voltage are recorded at a sampling rate of $58 \mathrm{kHz}$. In addition, the individual voltages at the faying surfaces and the contact surfaces electrode/sheet metal are recorded using the WeldAnalyst-system. The electrode force is measured by a piezoelectric sensor, which is automatically calibrated before welding. In addition, the electrode widening is detected during the working cycle time by the use of a capacitive position sensor. The electrode widening is defined by the distance difference in the direction of the $z$-axis between both electrodes. Another part of the process monitoring is the measurement of the

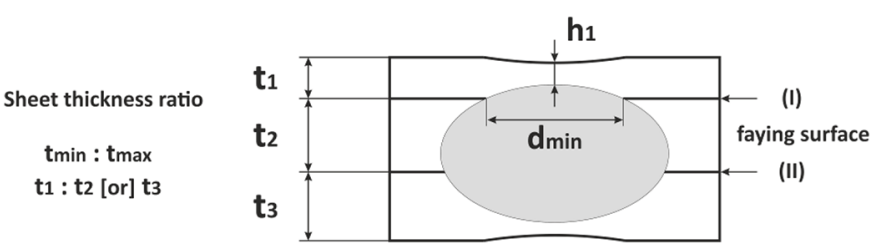

Fig. 1. Asymmetric three-sheet stack-up. oscillation of the upper electrode by using a laser vibrometer. The horizontal angle to the upper electrode is $\sim 45$ degree. The laser vibrometer is positioned according to the optimal focus diameter and the greatest possible visibility of the measuring system.

\section{Spot weld bonding - determination of the weldability lobe}

The procedure to determine the weldability lobe of a component is specified in [5,13]. In [7] it could be shown that with adjusted multiple impulse weldings, spot weld bonding of asymmetric three-sheet steel stack-ups is possible within a sufficient quality. The examined sheet stack-ups and the resulting welding current ranges in [7] are shown in Tables 1 and 2 .

The parameters shown in Table 2 were defined within an empirical study. Due to the preheat current, the adhesive is displaced and the sheet stack-up is conditioned to reduce the probability of welding spatters $[7,9]$. The Parameters (I) are suitable for resistance spot welding of non-bonded three-sheet stack-ups [9]. To create an opportunity to compare, these parameters are applied to adhesive-bonded components to define reference values. The Parameters (II) are specifically adapted for adhesivebonded components. The utilization of these parameters results in a significantly extended welding current range [7]. To investigate the influence of the electrode force on adhesive-bonded components, the parameters shown in Table 2 for both material combinations are utilized to an electrode force level of $3 \mathrm{kN}$. The resulting welding current ranges are shown in Table 3 .

It can be seen that Material Combination (I) reacts more sensitively to a changing electrode force due to the lower material strength. With a higher electrode force, the electrode indentation increases. Low strength materials deform easily, resulting in increased surface conductivities and reduced current density.

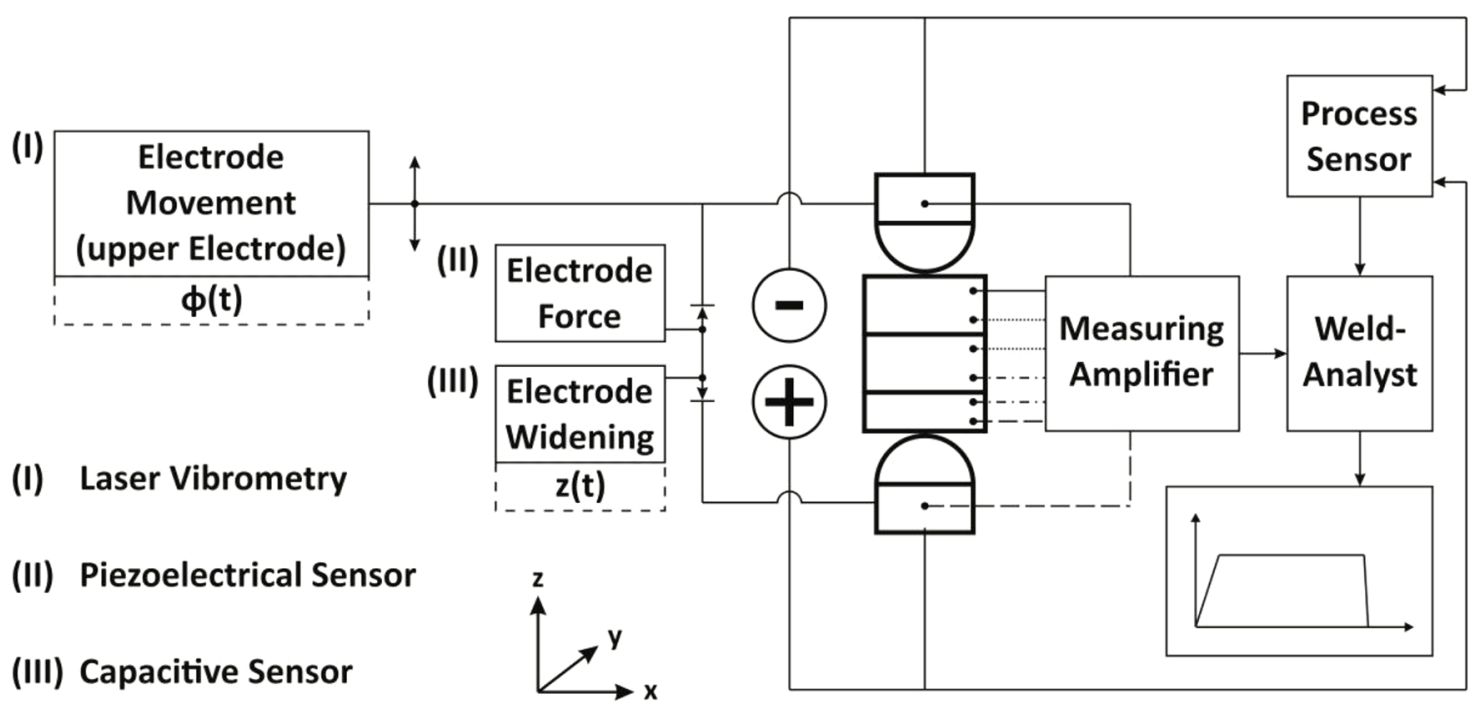

Fig. 2. Resistance spot welding system and online measurement device. 
Table 1. Material Combination (I) \& (II) [7].

\begin{tabular}{|c|c|c|c|c|}
\hline \multicolumn{2}{|c|}{ Material Combination (I) } & \multicolumn{2}{|c|}{ Material Combination (II) } & \multirow[t]{2}{*}{ Polarity } \\
\hline Material & Sheet thickness & Material & Sheet thickness & \\
\hline$\overline{\mathrm{DX}} 51 \mathrm{D}+\mathrm{Z}(1.0226)$ & $0.7 \mathrm{~mm}$ & $\mathrm{DX} 51 \mathrm{D}+\mathrm{Z}(1.0226)$ & $0.7 \mathrm{~mm}$ & + \\
\hline \multicolumn{2}{|c|}{ Adhesive (one-part epoxy based) } & \multicolumn{2}{|c|}{ Adhesive (one-part epoxy based) } & \\
\hline $\mathrm{DX} 51 \mathrm{D}+\mathrm{Z}(1.0226)$ & $1.5 \mathrm{~mm}$ & $22 \mathrm{MnB} 5(1.5528)$ & $1.7 \mathrm{~mm}$ & \\
\hline \multicolumn{2}{|c|}{ Adhesive (one-part epoxy based) } & \multicolumn{2}{|c|}{ Adhesive (one-part epoxy based) } & \\
\hline $\mathrm{DX} 51 \mathrm{D}+\mathrm{Z}(1.0226)$ & $1.5 \mathrm{~mm}$ & $22 \mathrm{MnB} 5(1.5528)$ & $1.7 \mathrm{~mm}$ & - \\
\hline
\end{tabular}

Table 2. Welding parameter - spot weld bonding of three-sheet steel stack-ups [7,9].

\begin{tabular}{lllllll}
\hline & & \multicolumn{2}{c}{ Material Combination (I) } & & \multicolumn{2}{c}{ Material Combination (II) } \\
\cline { 3 - 4 } \cline { 6 - 7 } & & Parameters (I) & Parameters (II) & & Parameters (I) & Parameters (II) \\
\hline Squeeze time & & $1000 \mathrm{~ms}$ & $1000 \mathrm{~ms}$ & & $1000 \mathrm{~ms}$ & $1000 \mathrm{~ms}$ \\
Preheat pulse & Current & - & $7.8 \mathrm{kA}$ & & $11.0 \mathrm{kA}$ & $5.5 \mathrm{kA}$ \\
& Preheat time & - & $250 \mathrm{~ms}$ & & $30 \mathrm{~ms}$ & $250 \mathrm{~ms}$ \\
Pause time & & - & $20 \mathrm{~ms}$ & & $20 \mathrm{~ms}$ & $20 \mathrm{~ms}$ \\
Main pulse & Current & $8.05-9.05 \mathrm{kA}$ & $7.40-9.60 \mathrm{kA}$ & & $6.00-7.15 \mathrm{kA}$ & $5.75-7.55 \mathrm{kA}$ \\
Hold time & Weld time & $350 \mathrm{~ms}$ & $350 \mathrm{~ms}$ & & $350 \mathrm{~ms}$ & $350 \mathrm{~ms}$ \\
Electrode force & & $300 \mathrm{~ms}$ & $300 \mathrm{~ms}$ & & $300 \mathrm{~ms}$ & $300 \mathrm{~ms}$ \\
\hline
\end{tabular}

Table 3. Welding current ranges - Material Combination (I) \& (II).

\begin{tabular}{llllll}
\hline Electrode force & \multicolumn{2}{c}{ Material Combination (I) } & & \multicolumn{2}{c}{ Material Combination (II) } \\
\cline { 2 - 3 } \cline { 6 - 7 } & Parameters (I) & Parameters (II) & & Parameters (I) & Parameters (II) \\
\hline $2 \mathrm{kN} \mathrm{[7]}$ & $8.05-9.05 \mathrm{kA}$ & $7.40-9.60 \mathrm{kA}$ & & $6.00-7.15 \mathrm{kA}$ & $5.75-7.55 \mathrm{kA}$ \\
$3 \mathrm{kN}$ & $9.15-10.20 \mathrm{kA}$ & $7.75-10.45 \mathrm{kA}$ & & $6.50-7.20 \mathrm{kA}$ & $5.90-7.45 \mathrm{kA}$ \\
\hline
\end{tabular}

The limits of the minimum and maximum welding current increase significantly with a higher electrode force. As a tendency, the welding current ranges increase slightly due to the use of a higher electrode force. This behavior is not as pronounced as with Material Combination (II) with higher material strength. High electrode forces result in a slight shift of the welding current ranges. Additionally, the size of the welding current ranges decreases with increasing electrode force. These correlations are shown in Figure 3 as a weldability lobe diagram.

\section{Spot weld bonding - influence of squeeze time}

For the following experiments the Material Combination (I)-(III) were examined as shown in Tables 1 and 4.

Depending on the squeeze time, the adhesive is displaced by the resulting electrode pressing. As a result, the dynamic electrical resistance and the electrical energy
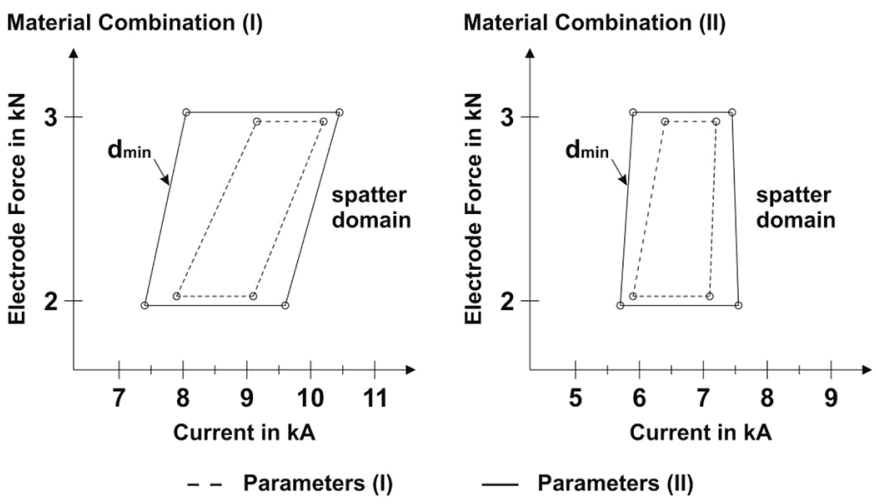

Fig. 3. Weldability lobe diagram.

generated during the weld time are reduced with a longer squeeze time. A schematic course of the dynamic electrical resistance during the weld time is shown in Figure 4. 

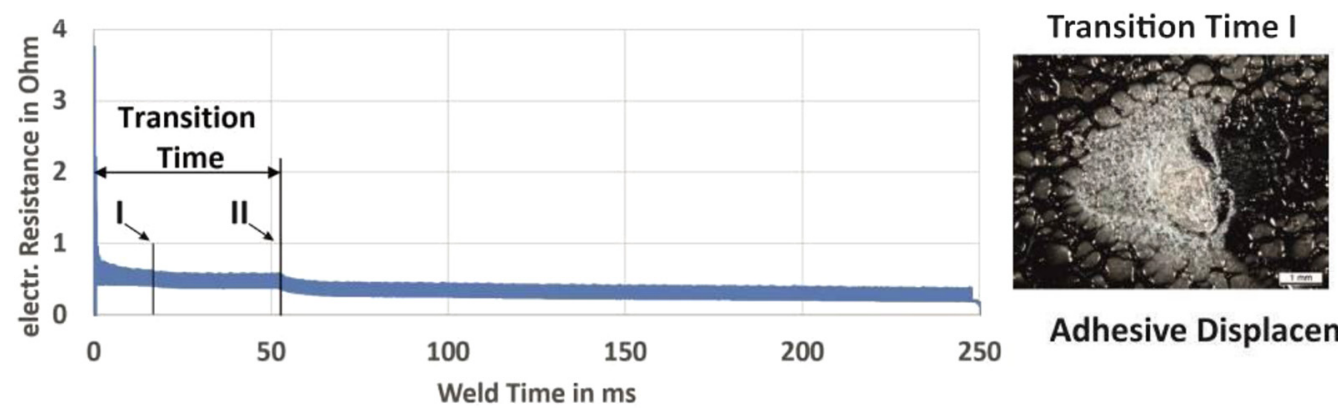

Transition Time II

Adhesive Displacement - Faying Surface

Fig. 4. Spot weld bonding - dynamic electrical resistance and adhesive displacement.

Table 4. Material Combination (III).

\begin{tabular}{lcc}
\hline \multicolumn{2}{c}{ Material Combination (III) } & Polarity \\
\cline { 1 - 2 } Material & Sheet thickness & \\
\hline DX51D + Z $(1.0226)$ & $0.7 \mathrm{~mm}$ & + \\
Adhesive (one-part epoxy based) & \\
HX340LAD $+\mathrm{Z}(1.0933)$ & $1.5 \mathrm{~mm}$ & \\
Adhesive (one-part epoxy based) & - \\
HX340LAD $+\mathrm{Z}(1.0933)$ & $1.5 \mathrm{~mm}$ & - \\
\hline
\end{tabular}

By initiating the welding current, the maximum peak of the dynamic electrical resistance rapidly decreases within the first milliseconds. Afterwards, the adhesive is displaced from the welding zone during the transition time. The displacement of the adhesive takes place continuously and the sheet metal coating begins to melt (Transition Time I). When the adhesive displacement is completed, the molten surface coating generates a conductive joint and the dynamic electrical resistance decreases (Transition Time II).

The length of transition time depends on the electrode force, squeeze time and material properties. The level of electrical resistance and thus the amount of electrical energy generated depends on these interrelationships. Figure 5 shows the shifts in transition time and electrical energy during the absolute weld time using Material Combination III as an example.

For these experiments, single pulse welds with an electrode force of $2 \mathrm{kN}$ and a weld time of $250 \mathrm{~ms}$ are used. The level of current was chosen to generate a comparable amount of electrical energy between the different material combinations (Material Combination I - $7.8 \mathrm{kA}$, Material Combination II - $5.5 \mathrm{kA}$, Material Combination III $7.0 \mathrm{kA}$ ). By using a short squeeze time, the high amount of electrical resistance persists within a long transition time. As a consequence, the electrical energy generated in these welds is higher compared to a longer squeeze time. However, there is a higher variation in the experimental results, which decreases with longer squeeze times. The experimental results for Material Combination I-III is shown in Figure 6.

The influence of the material properties on the adhesive displacement as dependent on squeeze time is shown in

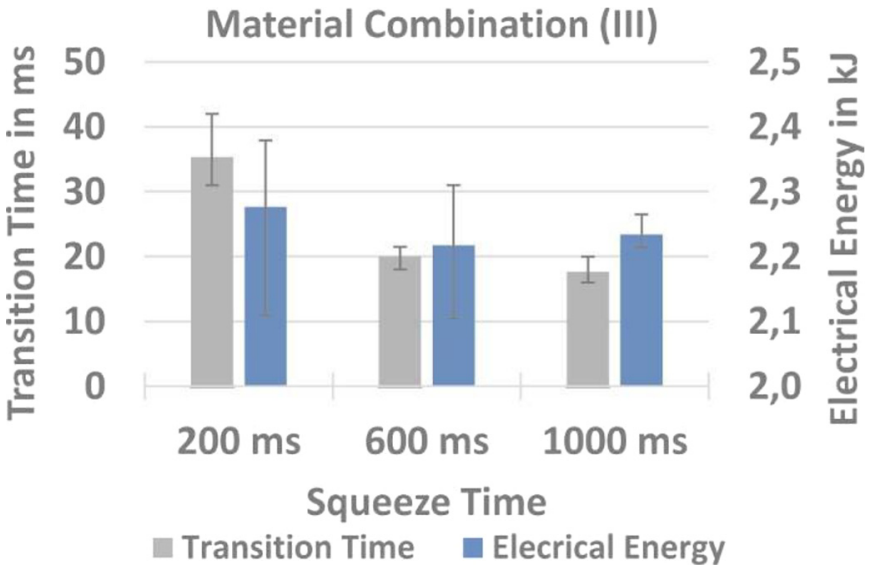

Fig. 5. Transition time and electrical energy.

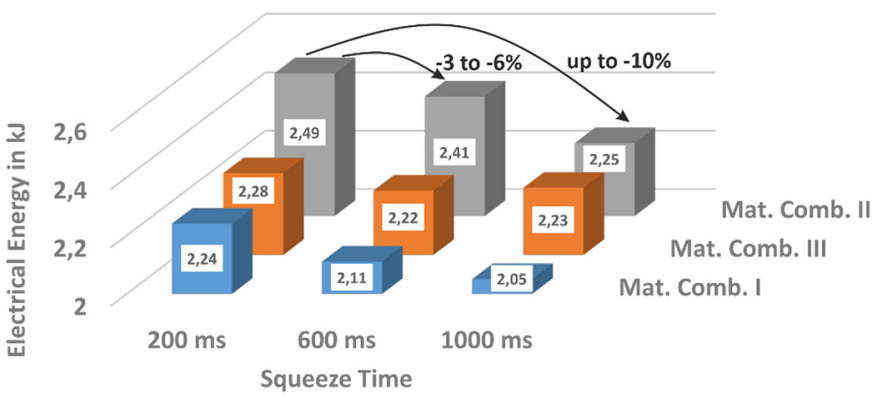

Fig. 6. Evaluation of electrical energy.

Figure 6. The correlations shown above can be demonstrated for each material combination. Depending on the squeeze time used, there is a maximum gap of $10 \%$ between the generated electrical energy for Material Combination I \& II and 3\% for Material Combination III. The correlations between the small difference in squeeze time between $200 \mathrm{~ms}$ and $600 \mathrm{~ms}$ are also clearly visible. Here the gap of electrical energy reaches a plateau between $3 \%$ and $6 \%$. The resulting electrical energy generated in the Material Combination (III) with a squeeze time of $600 \mathrm{~ms}$ and $1000 \mathrm{~ms}$ is comparable. However, there is a scattering in the measurement results so that the differences between these experiments cannot be illustrated (Fig. 5). A higher quantity of experiments is necessary to reduce the measurement scattering and to illustrate possible 

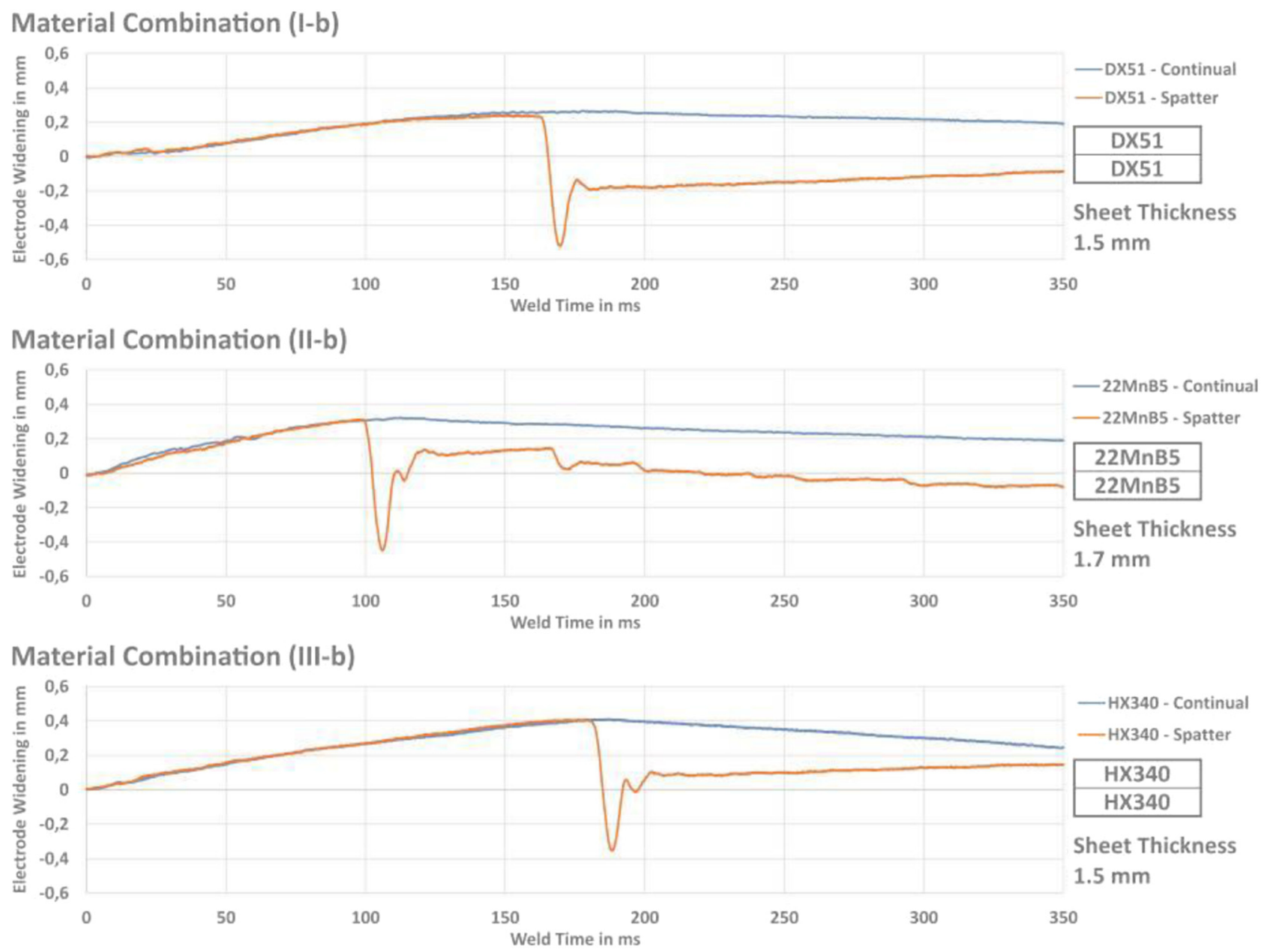

Fig. 7. Electrode widening during weld time.

differences for the Material Combination (III) with higher squeeze times. It can be assumed that the effect of a preheat current in a welding process is influenced by the selection of the squeeze time. The influence of different squeeze times on the possible change of a weldability lobe needs to be investigated in more detail.

\section{Resistance spot welding - process monitoring}

The occurrence of welding spatters in the area of resistance spot welding is unpredictable. Welding spatters are undesirable effects in the process that can result in a defective weld. With standard measurement devices and process monitoring of the dynamic electrical resistance, welding spatters can only be detected after they have occurred. Welding parameters in the vicinity of the spatter domain are unsuitable due to the high probability of the occurrence of welding spatters (Fig. 3). A welding process can be analyzed in real time with various online measurement devices [7-12]. The aim of the following experiments is the preventive detection of welding spatters by process monitoring on the basis of a capacitive sensor and laser vibrometry. For the creation of a first database and the verification of feasibility, the process monitoring experiments are based on non-bonded two-sheet steel stack-ups.

During welding, the electrodes widen due to the expansion of the formed weld nugget. Depending on the materials and process parameters used, the course of the electrode widening during welding provides information about the weld nugget formed. In the following, the twosheet steel stack-ups investigated are termed I-b, II-b and III-b in comparison to the three-sheets equivalents. The individual course of the electrode widening of a single pulse welding for different materials is shown in Figure 7.

The electrode widening is investigated by using singlepulsed resistance spot welding of two-sheet steel stack-ups. Here the weld time is $350 \mathrm{~ms}$ and the current for Material Combination I-b $11.0 \mathrm{kA}$, Material Combination II-b $7.6 \mathrm{kA}$ and Material Combination III-b $9.0 \mathrm{kA}$. The parameters used for every individual material combination are close to the spatter domain. Here the parameters and process conditions for a continual welding (without welding spatter) and a defective welding (with welding spatter) are the same. The spatters emerged by a defective welding can occur in a wide range of weld time and is not generally related to the maximum peak value of the electrode widening. 


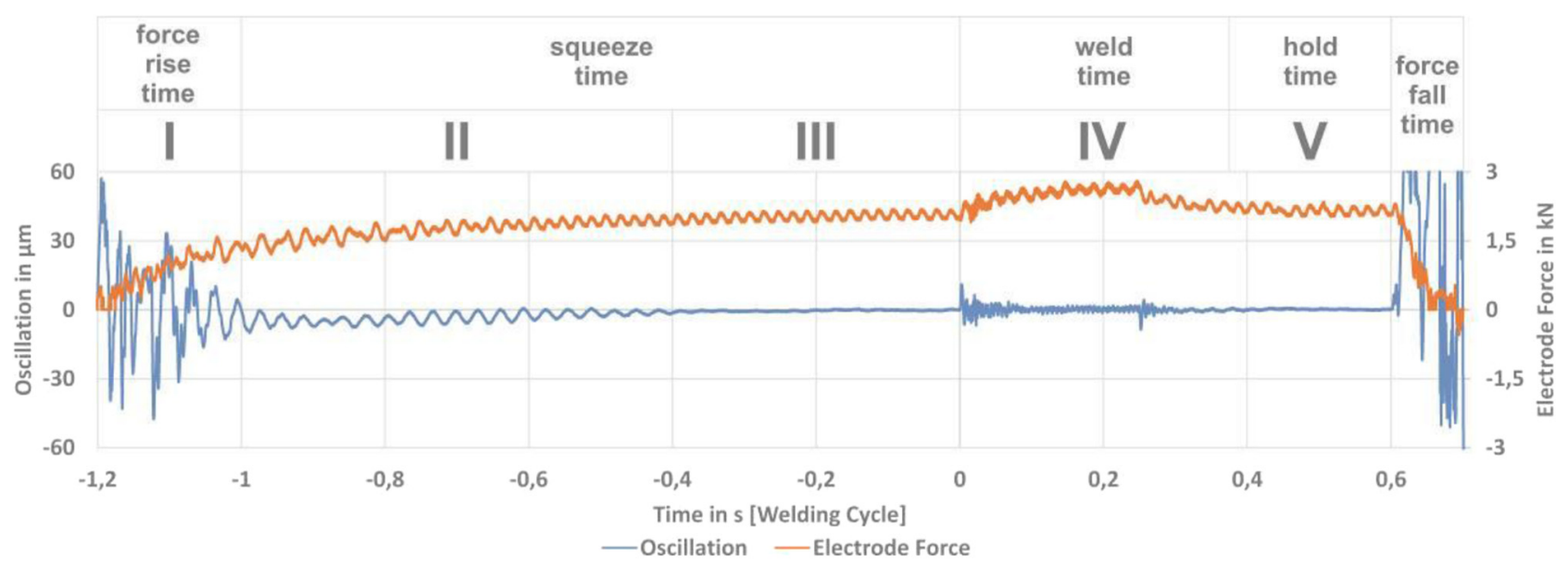

Fig. 8. Oscillation periods during welding cycle.

Table 5. Oscillation Period II.

\begin{tabular}{|c|c|c|c|c|c|c|c|c|c|c|}
\hline & \multirow[t]{2}{*}{$\begin{array}{l}\text { Electrode } \\
\text { force }\end{array}$} & \multicolumn{3}{|c|}{$\begin{array}{l}\text { Material Comb. (I-b) } \\
\text { DX51 }(2 \times 1.5 \mathrm{~mm})\end{array}$} & \multicolumn{3}{|c|}{$\begin{array}{l}\text { Material Comb. (II-b) } \\
22 \mathrm{MnB} 5(2 \times 1.7 \mathrm{~mm}) \\
\end{array}$} & \multicolumn{3}{|c|}{$\begin{array}{r}\text { Material Comb. (III-b) } \\
\text { HX340 }(2 \times 1.5 \mathrm{~mm})\end{array}$} \\
\hline & & Avg. & Max. & Min. & Avg. & Max. & Min. & Avg. & Max. & Min. \\
\hline \multirow{2}{*}{$\begin{array}{l}\text { Oscillation Period II } \\
\text { in } \mathrm{ms}\end{array}$} & $2 \mathrm{kN}$ & 473 & 480 & 470 & 647 & 740 & 600 & 460 & 470 & 450 \\
\hline & $5 \mathrm{kN}$ & 263 & 300 & 240 & 416 & 440 & 380 & 213 & 240 & 200 \\
\hline
\end{tabular}

For process monitoring by evaluation of the electrode widening, the gradient of the course, the height of the maximum peak and the corresponding time mark are of particular relevance to investigate the formation of the weld nugget. It can be seen that the courses of the electrode widening ("Continual" and "Spatter") are congruent for every material combination. In comparison to [10], the examination was performed under different process conditions. In this case, a preventive detection of weld spatters for the investigated material combinations was therefore not possible.

The initiation of the current in the welding process leads to an oscillating movement of the electrodes $[11,12]$. Simultaneously, an oscillation is initiated by collision between the electrodes and the sheet metals. During the working cycle time, a laser vibrometer focuses the upper electrode and records the movement and velocity of the oscillation. The electrode movement and the course of the electrode force are shown schematically in Figure 8.

At the beginning of the force rise time, the oscillation of the colliding electrodes decreases within $200 \mathrm{~ms}$ (oscillation period I). Thereafter, small oscillations are remained for $600 \mathrm{~ms}$ within the squeeze time (oscillation period II). In the range of "oscillation period III", the initiated oscillation is completely eliminated. When the current is introduced, a specific oscillation of the electrodes occurs depending on the material properties and parameters used (oscillation period IV). This range of oscillation can be analyzed for further process monitoring. At first it will be shown how long the oscillation persists due to collision of the electrodes and when this disturbing influence on the following measurement is eliminated. The Oscillation Period II for every material combination is shown in Table 5.

For these investigations, two-sheet steel stack-ups are joined by resistance spot welding. It can be seen that there are huge differences between the ferritic materials (DX51 \& HX340) and the martensitic material $(22 \mathrm{MnB} 5)$. The material combinations consisting of ferritic sheet metals have a high deformability and lead to a fast absorption of oscillations. Especially by using high electrode forces, the oscillations are eliminated within $300 \mathrm{~ms}$. Martensitic sheet metals such as $22 \mathrm{MnB} 5$ have a limited absorption capacity. Here the range of Oscillation Period II is wide and approx. $647 \mathrm{~ms}$ for $2 \mathrm{kN}$ electrode force, respectively, $416 \mathrm{~ms}$ for $5 \mathrm{kN}$ are required to eliminate the oscillations.

With initiating current, an oscillating movement of the electrodes occurs (Fig. 9). The course recorded can be defined in two separate ranges. In the heterogeneous range, the initiated oscillation decreases within approx. $60 \mathrm{~ms}$. Thereafter, the electrodes oscillate homogeneously within a steady range of amplitude and frequency. The process monitoring of the electrode oscillation is based on the first $70 \mathrm{~ms}$ of the weld time. This range consists of a superposition of different amplitudes and frequencies that can be evaluated by a Fourier analysis. In the following, ten continuous welds (without welding spatter) and ten defective welds (with welding spatter) were performed under the same process conditions. The performed welds are evaluated using Fourier analysis as shown in Figure 10.

The experiments were performed on two-sheet steel stack-ups consisting the material DX51 (1.5 mm). There 


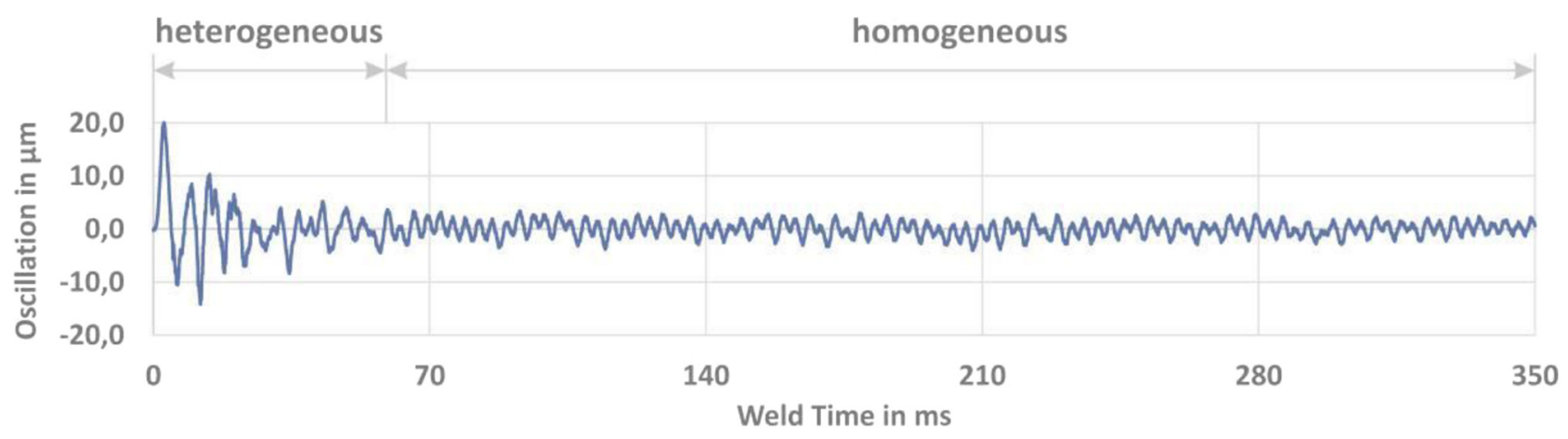

Fig. 9. Course of electrode oscillation during weld time.

\section{Welds without spatters}
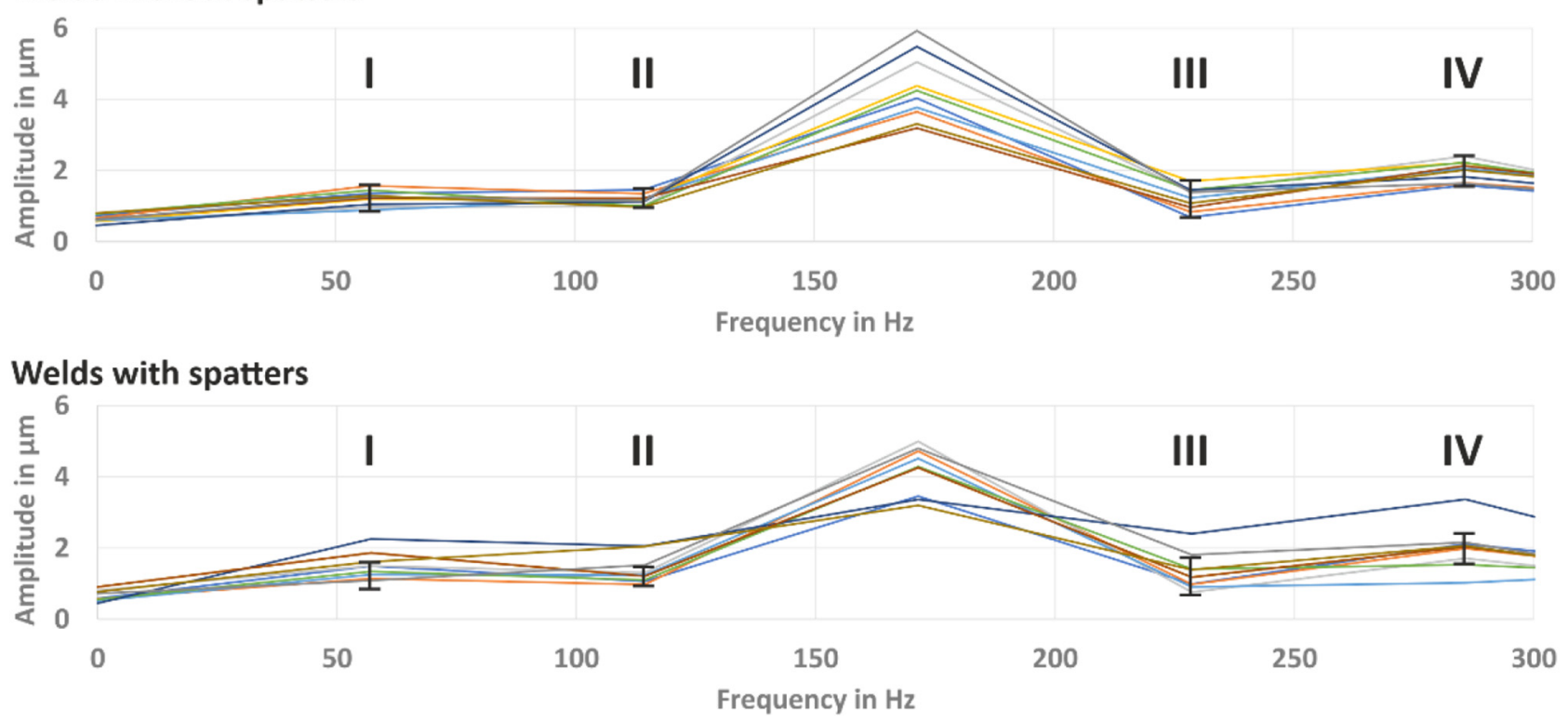

Fig. 10. Fourier analysis of electrode oscillation (0-70 ms of weld time).

are some differences between the frequency spectra of continuous and defective welds. A primary frequency of $171 \mathrm{~Hz}$ results for continuous and defective welds, whereby the amplitudes and distributions of the secondary frequencies differ greatly from each other. Defective welds result in a high distribution of the results and the amplitudes of the secondary frequencies are higher. Because continuous and defective welds have an identical main frequency, differentiation is only possible by evaluation of the secondary frequencies. In the analysis, the variance of the measurements is specifically reduced, so that the evaluation is limited to only a few frequency ranges, as shown in Table 6.

Based on the ten continuous welds, the individual amplitude ranges were determined to define validity limits. These validity limits were assigned to the defective welds in order to allow a comparability of the secondary frequency ranges. Because defective welds cause high fluctuations of the secondary frequencies, $80 \%$ of these welds exceed at least one of the defined validity limits. From the experimental results, a preventive detection of possible

Table 6. Validity limits for secondary frequency ranges.

Secondary frequency ranges

\begin{tabular}{lll}
\hline I & $57 \mathrm{~Hz}$ & $0,80-1,60 \mu \mathrm{m}$ \\
II & $114 \mathrm{~Hz}$ & $1,00-1,45 \mu \mathrm{m}$ \\
III & $228 \mathrm{~Hz}$ & $0,70-1,70 \mu \mathrm{m}$ \\
IV & $285 \mathrm{~Hz}$ & $1,65-2,40 \mu \mathrm{m}$ \\
\hline
\end{tabular}

defective welds is possible in most cases by Fourier analysis of the first $70 \mathrm{~ms}$ of the weld time.

\section{Conclusions}

In this paper, two material combinations were examined for their weldability lobes using spot weld bonding. By adaption of the preheat current, both material combinations can be welded in a sufficient weld current range for an 
electrode force of $2 \mathrm{kN}$ and $3 \mathrm{kN}$. Here the Material Combination I made of the low-strength steel DX51 reacts more sensitively to changing electrode forces.

The adhesive displacement by welding adhesivebonded sheet metals depends largely on the electrode force and squeeze time. It could be shown that with different squeeze times, a change in the electrical energy generated during the weld time occurs. By extending the squeeze time, the reduction of electrical energy generated during the weld time is about 3 to $10 \%$.

Furthermore, two methods were used to detect possible weld spatters preventively. Here different welds (continuous and defective welds) were performed under the same process conditions. A preventive detection of possible defective welds was not possible due to the evaluation of the electrode widening.

The use of a laser vibrometer for the detection of the electrode movement has a certain delay until a measurement is possible. Depending on the materials used and electrode force, between 213 and $647 \mathrm{~ms}$ are necessary to eliminate the oscillations that are produced by the electrode collision. For the examinations, the first $70 \mathrm{~ms}$ of weld time was evaluated by using a Foruier analysis. It could be shown that a preventive detection of defective welds is possible with a success rate of $80 \%$.

The process monitoring by using a laser vibrometer requires an adequate data base. The prerequisite is that the usual oscillation frequencies and amplitudes are known for each material combination. Furthermore, the coherences between defective welds and the distribution of the amplitudes by secondary oscillation frequencies have to be examined in more detail.

\section{References}

1. C.V. Nielsen, K.S. Friis, W. Zhang, N. Bay, Three-sheet spot welding of advanced high strength steels: Report, Weld. J. 90 (2011) 32-40

2. S. Schreiber, Untersuchungen zum Dreiblechschweißen: Report, Schweißen Schneiden 53, 2001
3. U. Dilthey, Schweißtechnische Fertigungsverfahren 1, Springer, Berlin, 2006

4. ISO 18278-3, Resistance Welding - Weldability - Part 3: Evaluation procedures for weldability in spot weld bonding, ISO Standard, Beuth, 2017

5. E SEP 1220-2, Prüf- und Dokumentationsrichtlinie für die Fügeeignung von Feinblechen aus Stahl - Teil 2: Widerstandspunktschweißen, Guideline, 2010

6. DVS 2920, Widerstandspunkt-, Buckel- und Rollnahtschweißen von Stahlfeinblechen bis $3 \mathrm{~mm}$ mit metallischen Überzügen, Guideline, DVS, 2000

7. S. Brechelt, H. Wiche, V. Wesling, Influence of pre-pulse in spot weld bonding of three-sheet steel stack-up, Weld. World 63 (2019) 771-782

8. S. Brechelt, H. Wiche, V. Wesling, Zeitverhalten und Einflussgrößen von applizierten Klebstoffschichten zwischen mehrschnittigen Fügepartnern beim Widerstandspunktschweißen, Conference Transcript, 3. Niedersächsisches Symposium Materialtechnik, 2019

9. H. Kerl, Ein Beitrag zur Standmengenerhöhung der Elektrodenkappen beim Widerstandspunktschweißen, Dissertation, Clausthal University of Technology, Lower Saxony, Germany

10. N. Mitzschke, M. Wohner, S. Jüttner, Widerstandsschweißen mit variabler Elektrodenkraft - Entwicklung und Einfluss eines Kraftprofils zur Erweiterung des Schweißbereichs von 22MnB5, Conference Transkript, 24. DVS-Sondertagung Widerstandsschweißen, Duisburg: GSI SLV, 2019

11. M. Tuchtfeld, S. Jüttner, K. Nagel, Oscillation resistance spot welding - a new approach for joining aluminum costeffective, Conference Transcript, Fügen im Karosseriebau, 2018

12. M. Tuchtfeld, S. Jüttner, K. Nagel, Verlängerung der Elektrodenkappenstandzeit und Optimierung der Gefügestruktur der Schweißlinse beim Punktschweißen von Aluminium durch einen neuen Verfahrensansatz, Conference Transcript, 24. DVS-Sondertagung Widerstandsschweißen, 2019

13. ISO 14327, Resistance Welding - Procedures for determining the weldability lobe for resistance spot, projection and seam welding, ISO Standard, Beuth, 2004

Cite this article as: Sascha Brechelt, Philipp Neef, Henning Wiche, Volker Wesling, Spot weld bonding - process behavior of three-sheet steel stack-ups and analysis strategies with online measuring methods, Manufacturing Rev. 7, 3 (2020) 